\title{
A Laboratory Investigation of the Effects of Saturated Steam Properties on the Interfacial Tension of Heavy-Oil/Steam System Using Pendant Drop Method
}

\author{
Madi Abdullah Naser ${ }^{1,2}$, Asep Kurnia Permadi ${ }^{1}$, Wisup Bae ${ }^{2}$, Wonsun Ryoo ${ }^{3} \&$ Septoratno Siregar ${ }^{1}$ \\ ${ }^{1}$ Department of Petroleum Engineering, Bandung Institute of Technology, Indonesia. \\ ${ }^{2}$ Department of Energy and Mineral Resources Engineering, Sejong University, South Korea \\ ${ }^{3}$ Department of Chemical Engineering, Hongik University, South Korea \\ Correspondence: Wisup Bae, Department of Energy and Mineral Resources Engineering, Sejong University, 98 \\ Gunja-dong, Gwangjin-gu, Seoul 143-747, South Korea. Tel: 822-3408-3969. E-mail: wsbae@sejong.ac.kr
}

Received: April 12, 2015

Accepted: May 4, 2015

Online Published: May 20, 2015

doi:10.5539/eer.v5n1p94

URL: http://dx.doi.org/10.5539/eer.v5n1p94

The research is financed by Department of Energy and Mineral Resources Engineering, Sejong University.

\begin{abstract}
For about a century, steam injection has been widely used as the most popular thermal recovery method for heavy-oil in sandstone reservoirs. In order to achieve higher recovery efficiency, which corresponds to the lowest possible value of residual oil saturation and economic success of steam injection projects, an accurate laboratory measurement of the interfacial tension between steam and heavy-oil is essential. However, laboratory investigation and visualization of the effects of steam injection on the interfacial tension between heavy-oil and steam as a function of saturation temperature and pressure is not well documented in the literature.

The objective of this study is to investigate the influences of the two main factors which affect the interfacial tension of heavy-oil and steam namely saturation pressure and temperature. An optical cell, which was fitted with a goniometer system and a procedure to generate steam for the measurement of interfacial tension have been used. The difference between the density of heavy-oil and steam, which was used for pendant drop measurements, was calculated at specific temperature and pressure conditions using Katz's method. Meanwhile, the density of steam was obtained from an international steam table.

The interfacial tension of heavy-oil/steam was measured in small intervals, ranging from 115 to 181 Celsius and 25 to 150 pounds per square inch. The results show that the interfacial tension decreases when the saturation temperature and pressure increases. This finding might be useful as an important reference for understanding and visualization the mechanism of interfacial tension during steam injection.
\end{abstract}

Keywords: pendant drop method, interfacial tension, saturation pressure, saturation temperature, heavy-oil, steam generation

\section{Introduction}

Injection of steam into a heavy-oil sandstone reservoir has become an important and successful oil recovery process in the last few decades because this method is capable of enhancing the oil production by reducing its viscosity and residual oil saturation in the swept zones of the reservoirs. This lower oil saturation, in turn, is related to the interfacial tension between the displacing fluid and the oil, which approaches zero. As a result, high recovery from the swept zones can be achieved (Huygens et al., 1995). Interfacial tension exists when there are two immiscible fluids (gas-liquid or liquid-liquid), which are in contact with a few large-diameter molecules. It is normally measured in dynes/cm (Donaldson \& Alam, 2008). The interfacial tension between gas and crude oil ranges from zero to approximately 34 dynes $/ \mathrm{cm}$ and it is a function of temperature, pressure, and compositions of both the hydrocarbon and aqueous phases (PetroWiki, 2013). The interfacial tension between the displacing and the displaced fluids in the reservoir is of importance for understanding the oil recovery mechanism (Guo \& Schechter, 1997), and it might affect the efficiency of the oil recovery process. 
A number of laboratory and theoretical studies have been conducted to investigate the mechanisms of the effects of temperature, pressure, and the composition of each phase on the interfacial tension of crude-oil/brine systems (McCaffery, 1972; Wang \& Gupta, 1995; Hjelmeland \& Larrondo, 1986), water/bitumen systems (Rajayi \& Kantzas, 2011), and gas/water systems (Rushing, et al., 2008; Okasha \& Al-Shiwaish, 2010). However, experimental study of the effects of high saturation temperature and pressure on heavy-oil/steam interfacial tension was not well documented in the literature. There was only one study which was related to the interfacial tension measurement of light-oil (n-decane and n-tetradecane)/steam systems. Huygens, et al. 1995 measured the interfacial tensions between $n$-decane, n-tetradecane, mixtures (60-40 weight \%) of n-decane and n-tetradecane and saturation steam, using image processing techniques at the temperature (ranging from $100^{\circ} \mathrm{C}$ to $135^{\circ} \mathrm{C}$ in 5 ${ }^{\circ} \mathrm{C}$ intervals) and saturation pressure conditions. First, the experiment was performed with increasing temperature, and second, it was carried out with decreasing temperature. However, the mechanisms and procedures of steam generation were not clearly explained in their study. They observed that the interfacial tension of oil/steam systems tends to decrease with increasing temperature at saturation pressure conditions. Also recently, Yaser, et al. 2012 measured the interfacial tension between steam and Athabasca oil bitumen empirically using pendant drop method with two types of different bitumen. They measured the interfacial tension at several temperatures, ranging from $120^{\circ} \mathrm{C}$ to $220^{\circ} \mathrm{C}$ in $20^{\circ} \mathrm{C}$ intervals, and saturation pressure conditions. They observed that the interfacial tension between Athabasca oil bitumen and steam also decreased when temperature and pressure increased.

\subsection{Measurement of Interfacial Tension in Fluid-Fluid Systems Methods}

Several methods have been utilized to analyze and measure the interfacial tension between two immiscible fluids at different conditions. Those methods were reviewed in detail by Drelich, et al. 2012. In general, those techniques, such as Wilhelmy plate and Du Nouy ring methods, can be used for direct measurement of the interfacial tension by using a microbalance. Maximum bubble pressure and growing drop techniques can be used to measure the maximum pressure to force a gas bubble into a liquid while pressure is continuously changed and monitored when the bubble is growing. Capillary rise and drop volume techniques are used to analyze the balance between capillary rise and drop volume or weight. Pendant drop and sessile drop techniques are used to analyze the drop profile sitting on a solid surface or hanging profile.

\subsection{Pendant Drop Technique}

The pendant drop technique is an old-fashioned and quick method in which the interfacial tension is measured between two liquids (Worthington. 1881). Applying this technique for interfacial tension measurement requires a camera with high-magnification lens to record the shape of the drop. In this method, the maximum diameter and the ratio between that parameter and the diameter at a point where the distance starting from that point to the drop apex is of maximum diameter have been used to evaluate the size and shape parameters as shown in Figure.1. In order to determine the interfacial tension between steam and heavy-oil from drop profile, two parameters should be experimentally determined which are the radius of curvature at the drop apex $R_{o}$ and the shape factor $\beta$, then the interfacial tension can be calculated by using Equation 1 to Equation 4. (Herd, et al. 1992).

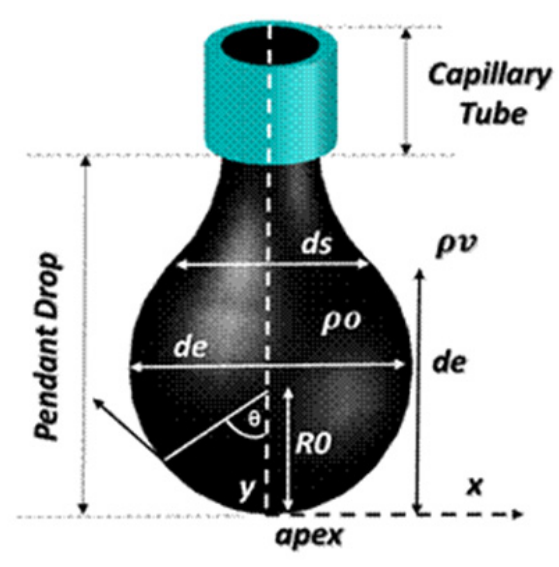

Figure 1. A close-up 3D view of pendant drop measurement. (After Naser et al., 2015) 


$$
\begin{gathered}
\gamma=\frac{\Delta_{\rho} g R_{o}^{2}}{\beta} \\
S=\frac{\mathrm{ds}}{\mathrm{de}} \\
\beta=0.12836-0.7577 S+1.7713 S^{2}-0.5426 S^{3} \\
R_{o}=\frac{d e}{2\left(0.9987+0.1971 \beta-0.073 \beta^{2}+0.34708 \beta^{3}\right)}
\end{gathered}
$$

\subsection{Objectives}

The main objectives of this study are to investigate and visualize the influences of the two main factors affecting the interfacial tension of heavy-oil and steam and its parameters which are high saturation pressure and temperature. To achieve that, an experimental technique and corresponding procedures are developed to generate steam within a small optical cell. Steam is generated in this equipment by supplying discontinuous heat energy to water. In this case, the water is continuously injected into the closed optical cell at high saturation temperature conditions. After steam is generated, drop image processing technique, using a Goniometer/Tensiometer with DROP_image Advanced-p/n 290-U1, is applied to measure the interfacial tension of the heavy-oil/steam system at elevated saturation temperature and pressure using the pendant drop method.

\section{Experimental Materials}

All interfacial tension measurement experiments are conducted using one specific type of dead heavy-oil at high saturation temperature and pressure condition. This heavy oil comes from a sandstone reservoir in Duri Field located in Indonesia. The density and viscosity of the heavy oil are $20^{\circ} \mathrm{API}$ and $486.584 \mathrm{cp}$, respectively, at atmospheric pressure and $15^{\circ} \mathrm{C}$. The true boiling point (TBP) distillation data according to the ASTM D-2892 Standard was used for characterizing the heavy oil composition. Table 1 summarizes the composition and density of the heavy-oil resulted from the experiment that was done in this study. The asphaltene content is determined according to the modified ASTM method by Wang and Buckley 2002. The ASTM procedure specifies that a volume of n-pentane that is 40 times the volume of the aliquot of oil should be added. The resulted asphaltene content of this heavy oil is about $1.44 \% \mathrm{wt}$. The experimental saturation pressure and saturation temperature ranges from 25 psia to 150 psia and from $115{ }^{\circ} \mathrm{C}$ to $181{ }^{\circ} \mathrm{C}$, respectively, for both steam generation and interfacial tension measurements.

Table 1. Composition of the heavy oil based on the true boiling point distillation data

\begin{tabular}{lccccc}
\hline Composition & $\begin{array}{c}\text { Temperature } \\
\text { Cut Point }\left({ }^{\circ} \mathrm{C}\right)\end{array}$ & $\begin{array}{c}\text { Density } \\
(\mathrm{g} / \mathrm{cc})\end{array}$ & $\begin{array}{c}\text { Average } \\
\text { Molecular Weight }\end{array}$ & $\begin{array}{c}\text { Weight } \\
\%\end{array}$ & $\begin{array}{c}\text { Cumulative } \\
\text { Weight } \%\end{array}$ \\
\hline Light Naphtha & 80 & 0.68 & 104 & 0.2 & 0.2 \\
Medium aphtha & 150 & 0.77 & 116 & 1.5 & 1.7 \\
Heavy Naphtha & 200 & 0.83 & 142 & 2.6 & 4.3 \\
Kerosene & 260 & 0.87 & 172 & 4.8 & 9.1 \\
Atmosphere Gas Oil & 340 & 0.91 & 212 & 12.5 & 21.6 \\
Light Vacuum Gas Oil* & 450 & 0.93 & 324 & 18.1 & 39.7 \\
heavy Vacuum Gas Oil* & 570 & 0.93 & 476 & 16.5 & 56.2 \\
Vacuum Residue & - & 0.97 & 1020 & 43.8 & 100 \\
\hline * Vacuum distillation was conducted under 2.66 mbar. & Density of the used heavy oil was measured as 0.94 \\
g/cc. & \multicolumn{5}{l}{} \\
\hline
\end{tabular}

\section{Experimental Apparatus}

The apparatus consists of a small optical cell used for steam generation and an image analyzing system (Goniometer/Tensiometer with DROP_image Advanced -p/n 290-U1) used for interfacial tension measurement.

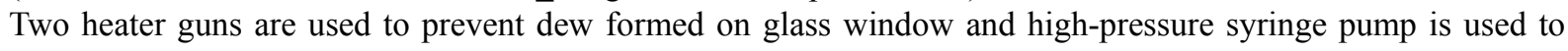


inject oil and water into the cell. Upper and lower cartridge heaters are used to heat the cell to the required saturation temperature. Temperature sensors, attached at outside and inside the cell, and controlling box are used for controlling the cell temperature. There are also pressure sensors, a light source, and a video camera. Figures 2 and 3 show a schematic diagram of the equipment's real appearance used for the steam generation and interfacial tension measurement in this study.

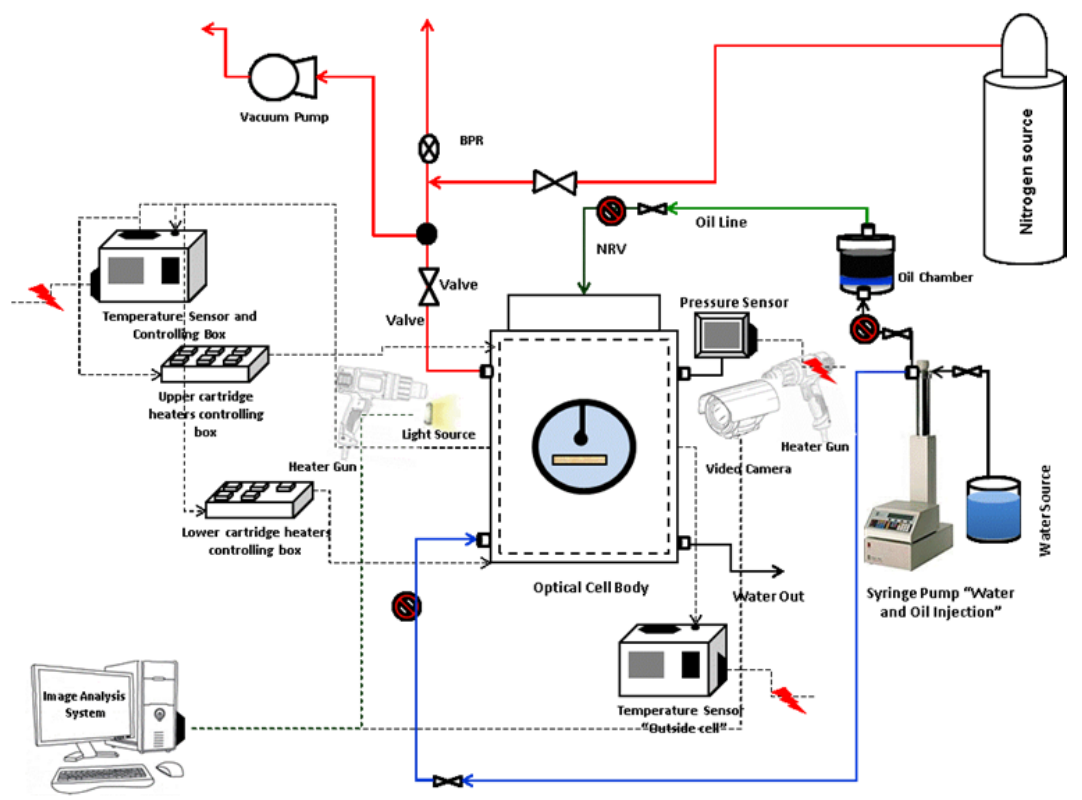

Figure 2. Schematic diagram of high-pressure high-temperature optical cell experimental setup. (After Naser et al., 2015)

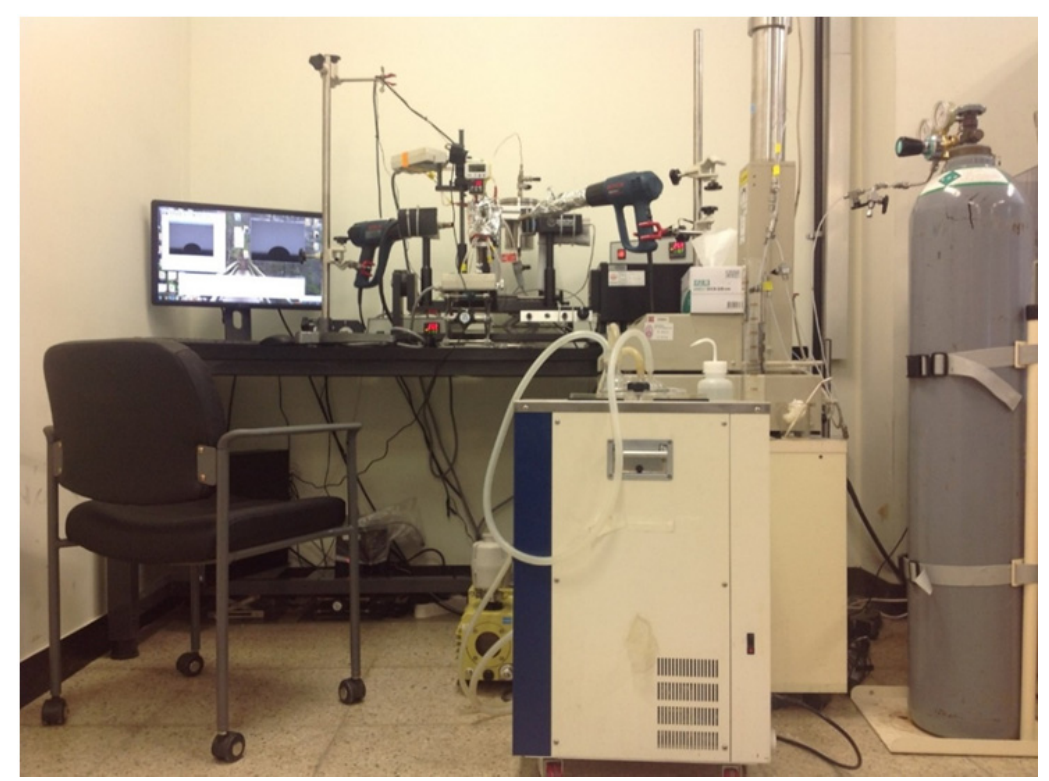

Figure 3. High-pressure high-temperature optical cell's apparatus. (After Naser et al., 2015)

\section{Procedure of Experiment}

The following seven steps are used in the procedure for preparing the equipment, which is utilized for steam generation as well as interfacial tension measurement. They are shown in Figure 4 and described in detail as follows. 
A- Experimental Preparation

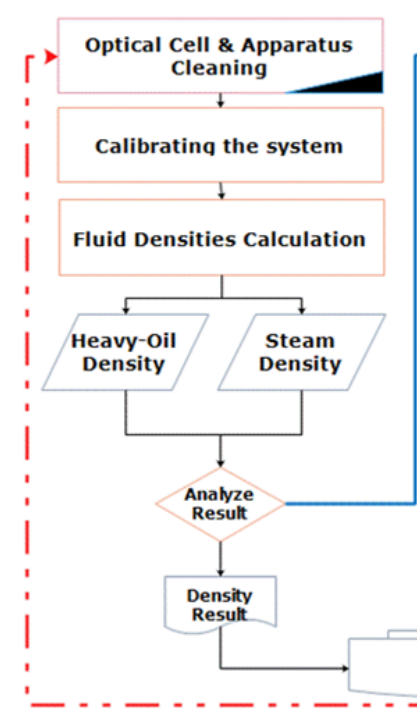

B- Steam Generation

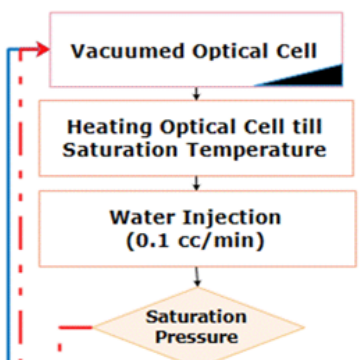

'

Noti

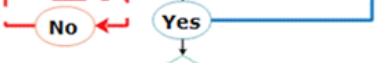

I

Analyze
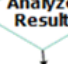

Steam

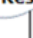

Experiment Result

Figure 4. Experimental flow chart procedures of experiment preparation, steam generation, and interfacial tension used in this study

\subsection{The first step}

In order to generate steam, measure and record the accurate values of interfacial tension, cleaning must be done before each experiment is performed. The optical cell, glass windows, connection tubes, and valves in the system are cleaned with toluene and flushed by hot water to remove all oil contaminants which may contact with glass windows and cell surface or plug in the tube.

\subsection{The second step}

In order to calculate correct and accurate interfacial tension values, the magnifications of the video and picture capturing devices must be known. In the calibration step, the program measures a known-size object, and the vertical and horizontal size of the pixels are calculated automatically. The calibration procedure must be performed every time when the magnification of the optical device is changed (Finn. 2012).

\subsection{The third step}

In order to measure the interfacial tension of heavy-oil and steam using pendant drop method, the difference between density of heavy-oil and steam is required. In-house software is utilized for heavy-oil density calculation at specific temperature and pressure conditions using Katz's method (Ahmed. 1989). The density of steam is obtained from the steam tables (Wolfgang, et al. 2008).

\subsection{The fourth step}

In order to generate pure steam (nearly $100 \%$ quality) within the optical cell, the cell and its connections must be vacuumed by a vacuum pump before every experiment. This procedure is used to reduce any gases that possibly affect the saturation steam pressure and temperature. After all systems have been vacuumed, the cell is directly heated to the required saturation temperature while the temperature outside the cell is kept to be $1^{\circ} \mathrm{C}$ larger than that inside the cell to reduce heat loss during steam generation. Also, it is to keep the process running as close as possible to a desired set point of saturation steam temperature.

\subsection{The fifth step}

In order to clearly monitor and to prevent quick condensation, the water is injected into the cell at the rate of $0.1 \mathrm{ml} / \mathrm{min}$ by ISCO pump. At the beginning, the cell's pressure and ISCO pump's pressure will gradually increase with the continuous water injection until both pressures stabilize. In this procedure, both pressures need to reach a certain value and they need to be stabilized. In addition to that, the inside and outside temperatures of the cell also need to be stabilized. At that point, the heavy oil dropping and hanging procedure can be commenced. If one of those requirements is not satisfied, then one needs to repeat the steam generation procedure all over again as shown in Figure. 4. 


\subsection{The sixth step}

In order to minimize the volume and maximize the size of the oil pendant drop during dropping and hanging procedure, the oil must be injected inside the cell using a needle which has optimum outside and inside diameters. After the steam is successfully generated, the heavy-oil is injected and held at the bottom of the needle tip. The volume of the droplet is carefully controlled by a valve and syringe pump. If the volume cannot be controlled and held, it is needed to repeat the experiment started from the apparatus cleaning procedure, as shown in Figure 4. Once the volume of pendant drop has been controlled and held successfully, the interfacial tension measurement procedure begins.

\subsection{The seventh step}

In order to more realistically simulate the conditions of the reservoir and to achieve reliable interfacial tension results, the oil droplet should be immersed in the steam for several minutes before the interfacial tension measurement began. This time allows the surface between the heavy-oil and the steam to reach an equilibrium condition. Then, the measurement is commenced after the droplet has been in equilibrium and no more light components of the heavy oil are evaporated.

\section{Experiment Results and Discussions}

Since the pendant drop method is the most adaptable method not only for high pressure but also for a wide range of high temperatures, it is selected for measuring the heavy-oil/steam interfacial tension in this study. In addition, it is an absolute, simple, and accurate method compared with other methods or techniques, which are empirically derived or need further correction to the measured data.

In this section, the results of heavy oil density, steam density, density difference, steam generation, and measurements of heavy-oil/steam interfacial tension at saturation pressure of $25,50,100$, and $150 \mathrm{psia}$ and temperature of $115,138,164$, and $181^{\circ} \mathrm{C}$ conditions is presented. In addition, it should be noted that these experiment results are only preliminary results, because all the experiments have not been completed yet (not until all required saturation temperatures and saturation pressures can be achieved) due to technical problems and increases in heat losses at the evaluated saturation temperatures. However, the findings demonstrated by these results may provide a good indicator of the relationships between heavy-oil/steam interfacial tension, saturation pressure, and saturation temperature under reservoir conditions.

\subsection{Results of Heavy-Oil and Steam Density Calculation}

The calculations of the fluid densities, which are required for interfacial tension measurement, are similar to that in many of previous studies in which empirical correlations are used to estimate the fluid density. Table 2 shows the heavy-oil density, steam density, and density difference as a function of saturation temperature and saturation pressure. From Figure 5 it can be seen that the density of steam increases with temperature and pressure. Since the steam is in the form of gas phase, pressure has a greater effect than temperature on its density. Meanwhile, the density of heavy-oil decreases with temperature and pressure. Since it is liquid then temperature has a greater effect than pressure on its density as shown in Figure 6.

Table 2. Steam density, heavy-oil density, and density difference as a function of saturation temperature and saturation pressure

\begin{tabular}{ccccc}
\hline $\begin{array}{c}\text { Saturation } \\
\begin{array}{c}\text { Steam Pressure } \\
(\mathrm{psia})\end{array}\end{array}$ & $\begin{array}{c}\text { Saturation Steam } \\
\text { Temperature }\left({ }^{\circ} \mathrm{C}\right)\end{array}$ & $\begin{array}{c}\text { Heavy Oil } \\
\text { Density }(\mathrm{g} / \mathrm{cm} 3)\end{array}$ & $\begin{array}{c}\text { Steam Density } \\
(\mathrm{g} / \mathrm{cm} 3)\end{array}$ & $\begin{array}{c}\text { Difference } \\
\text { Density }(\mathrm{g} / \mathrm{cm} 3)\end{array}$ \\
\hline 25 & 115 & 0.8080 & 0.0010 & 0.8070 \\
50 & 138 & 0.8023 & 0.0019 & 0.8004 \\
75 & 153 & 0.7972 & 0.0028 & 0.7944 \\
100 & 164 & 0.7931 & 0.0036 & 0.7895 \\
150 & 181 & 0.7854 & 0.0053 & 0.7801 \\
\hline
\end{tabular}




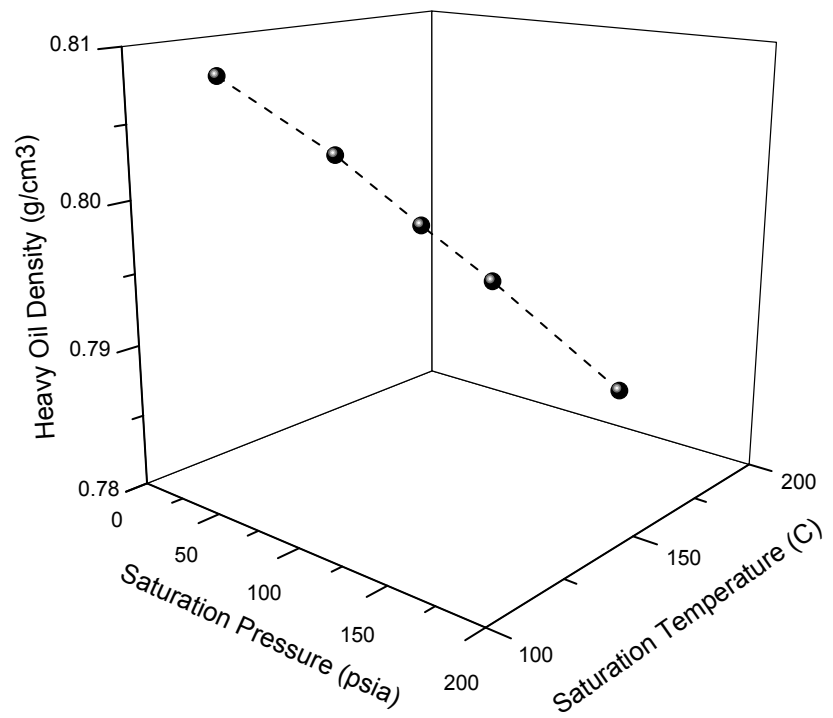

Figure 5. Heavy oil density as a function of saturation temperature and saturation pressure

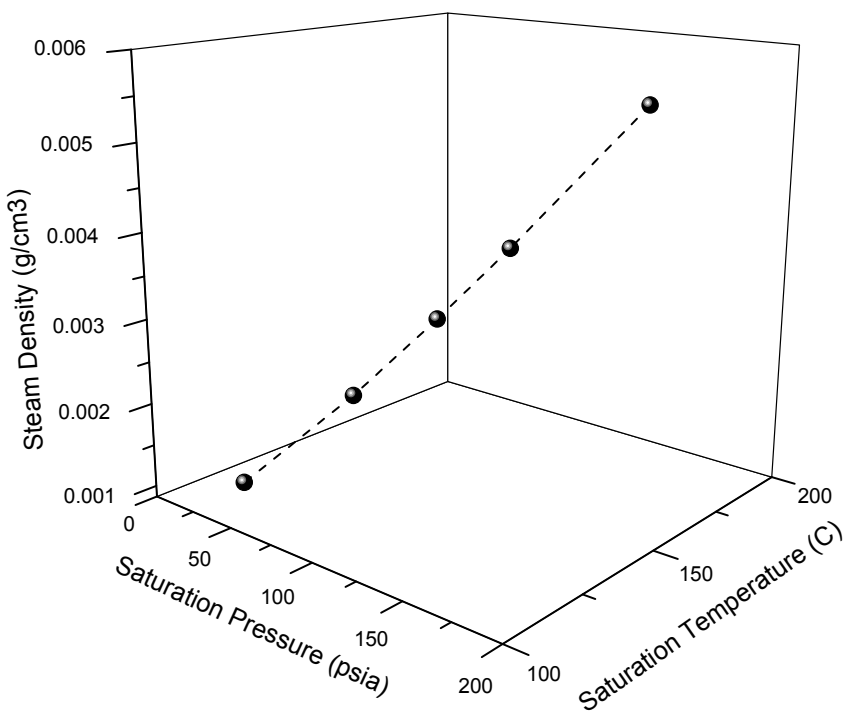

Figure 6. Steam density as a function of saturation temperature and saturation pressure

\subsection{Result of Steam Generation}

In the fifth procedure, it was pointed out that the cell's pressure or steam pressure in all the steam generation experiments were increased gradually by continuous water injection until they reached and are stabilized at 25 , 50, 100, and 150 psia as shown in Figure 7. Those constant pressures are called saturated steam pressure and the steam quality at the beginning of the stabilized line is nearly $100 \%$. In those experiments, when the saturated steam pressures reached certain values and are stabilized, the interfacial tension measurement begins. From Figure 8 and Table 3, it can be observed that the values of the saturated steam pressure, which corresponds to a saturated steam temperature, obtained from this experiment are exactly the same with the values provided in the international steam tables. In this experiment, the increase in heat loss during steam generation is largely the cause of not completing the experiment until the required saturation temperature is achieved. The other reason is some technical problems. 


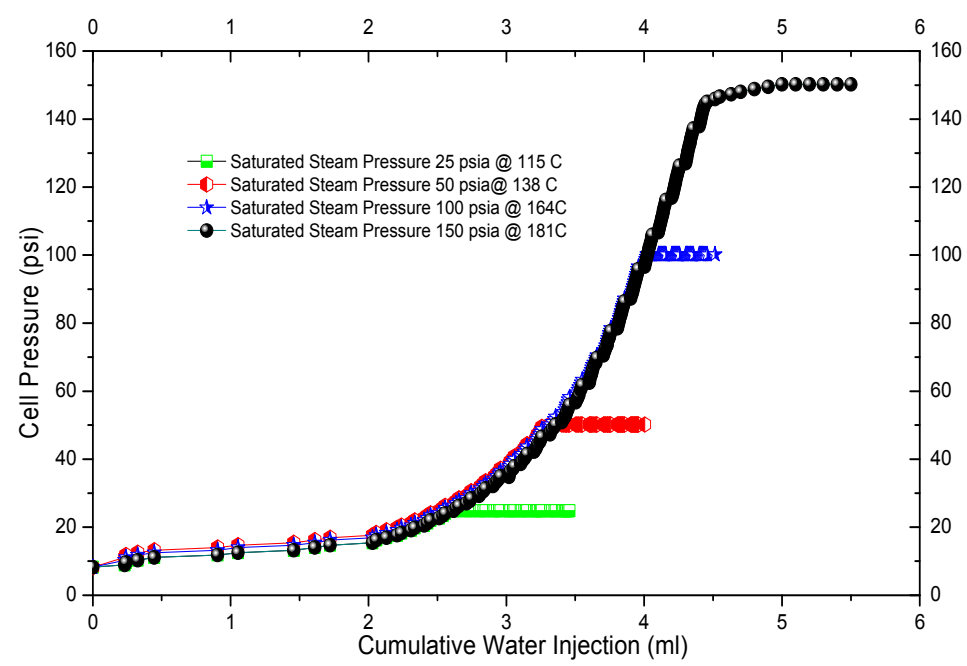

Figure 7. Saturation steam pressure results at different saturation temperature and saturation pressure

Table 3. Saturation pressure vs. saturation temperature of this study and international steam tables

$$
\text { Temperature (C) Saturation Pressure (psia) }
$$

\begin{tabular}{ccc}
\hline & This Study & Steam Table \\
\cline { 2 - 3 } 115 & 24.9 & 24.94 \\
138 & 50.2 & 49.53 \\
153 & 75.6 & 74.78 \\
164 & 100.2 & 99.15 \\
173 & 125.6 & 124.45 \\
181 & 150.2 & 149.49 \\
188 & 175.6 & 174.18 \\
194 & 200.2 & 198.98 \\
\hline
\end{tabular}

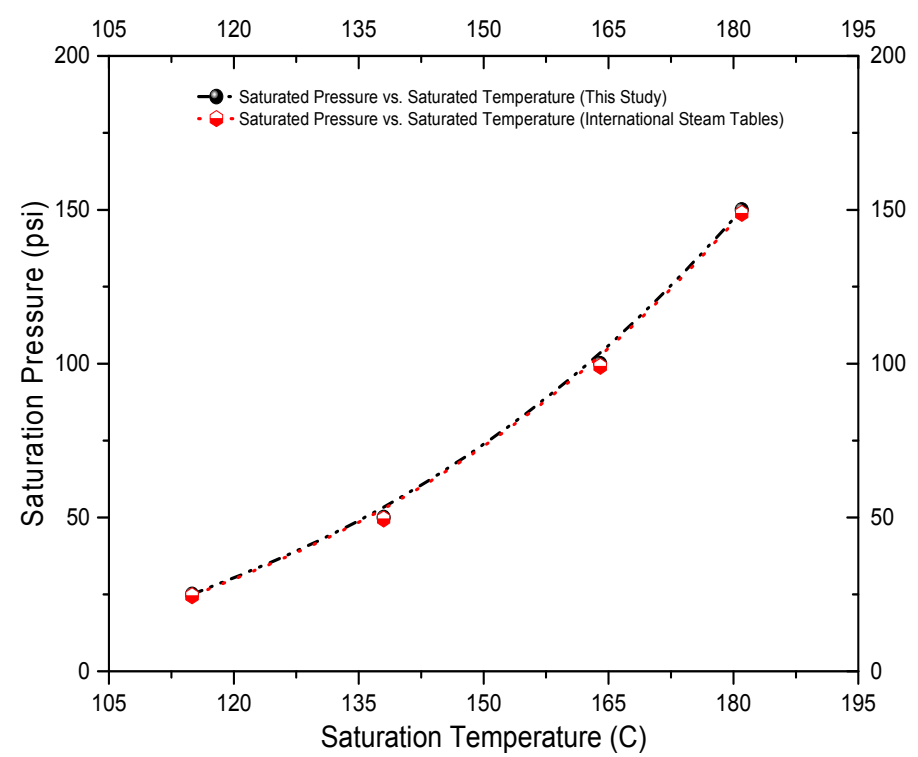

Figure 8. Comparison of saturation pressure vs. saturation temperature of this study and international steam tables 


\subsection{Results of Interfacial Tension Experiments}

In this section, the outcomes of measuring heavy-oil/steam interfacial tension by the pendant drop method are shown. Before starting the experiment, the system is calibrated to prove the validity of the experimental system and measured parameters. The surface tension measurement of distilled water/air at standard condition $\left(25^{\circ} \mathrm{C}\right.$ and atmospheric pressure) in this study by the pendant drop method is $71.95 \mathrm{mN} / \mathrm{m}$. In addition, similar calibration result of the surface tension of distilled water/air at standard condition was also presented by Vargaftik, et al. (1983) in air/water systems, which is $71.99 \mathrm{mN} / \mathrm{m}$. In order to minimize the errors of interfacial tension measurement, each experiment has been repeated three times which is denoted as Test\#1, Test\#2, and Test\#3). Each test has a maximum number of measuring points, which is around 3500, with the time interval between two consecutive points is one second. The interfacial tension, the shape factor, the radius of curvature at the heavy oil drop's apex, the drop surface area, the drop volume, the contact angle at the drop limit (horizontal) hairline, the total height measured from hairline to apex, the maximum width, the maximum of optimizations performed, and errors or other parameters may be obtained by using the method.

In order to achieve an accurate interfacial tension measurement, equilibrating the system is one of the most important steps in the procedure. Once the oil droplet is successfully formed, its volume should be minimum and the size at the tip of the needle should be maximum. After that, it is suspended inside the optical cell for several minutes before the measurement begins. In order to get equilibrium interfacial tension value, all the measurements are conducted at different aging time during which the oil drop will be exposed to steam. The equilibrium interfacial tension is a static value, which reaches and stabilizes at a certain point. This value will be different at different periods of aging time ranging from 33 to $50 \mathrm{~min}$ after the oil drop has been exposed to steam. During the aging time, the steam will dissolve in the heavy oil or vice versa. Figure 9 through Figure 12 show the results of just one of the three tests at the saturation pressures of $25,50,100$, and 150 psia and temperatures of $115,138,164$, and $181^{\circ} \mathrm{C}$. In general, it can be observed that the steam injection affects the heavy-oil/steam system interfaces.

Figures 9 (a), 10 (a), 11 (a), and 12 (a) show the shape factors for all of the systems studied. They show that the steam and aging time do have effects on shape factors of the oil drop. It can be seen that the shape factor increases when the aging time increases in all the systems. This effect on the drop shape is reflected by the ratio of ds/de of the oil drop. The maximum oil drop diameter (de) decreases due to the steam (the pendant drops tend to be smaller), while the diameter at the distance de from the drop apex (ds) remains relatively the same. As a result, the shape factor $(\beta)$ increases as it is clearly shown in the figures.

Figures 9 (b), 10 (b), 11 (b), and 12 (b) show the radius of curvature at the oil drop apex $\left(\mathrm{R}_{\mathrm{o}}\right)$ for all of the systems studied. It can be seen that it decreases when the aging time increases. This phenomenon is reflected by an increase in the value of the shape factor $(\beta)$ and a decrease in the maximum drop diameter of the oil drop. As the volume of the oil drop tends to be smaller, the radius of curvature at the oil drop apex decreases.

From the results, the interfacial tension decreases when the aging time increases for all of the systems. This can be illustrated in Figures 9 (c), 10 (c), 11 (c), and 12 (c). However, the effect of aging time on the equilibrium interfacial tension is a slightly different. The interfacial tension decreases drastically during the first $8.33 \mathrm{~min}$ of exposure to the steam. From $8.33 \mathrm{~min}$ to $25 \mathrm{~min}$, the interfacial tension decreases moderately and after that it begins to stabilize.

Figures 9 (d), 10 (d), 11 (d), and 12 (d) show a digital photograph of the droplet for the heavy-oil/steam systems. There are some important phenomena which have been observed during the equilibrium and aging time periods. Sometimes, a pendant drop volume is larger than required. Because of that, it tends to be pulled downward. Inversely, when it is smaller, the oil drop moves up and down along the needle tube until it stabilizes at the bottom of the needle tip. After stabilized condition is achieved, most of the pendant drops can stay at the bottom of the needle tip for several hours but some of them stay for lower period of time. The end result of this is uncompleted-shape pendant drop as clearly shown in Figure 13. This same phenomenon was also observed by Daoyong \& Yongan 2004 for crude-oil/ $/ \mathrm{CO}_{2}$ interactions. Using the capillary rise method, which is the oldest surface tension method, they explained this effect by the balanced forces between the tension force (heavy oil with needle) and gravity force of the oil drop as well as the wettability. 


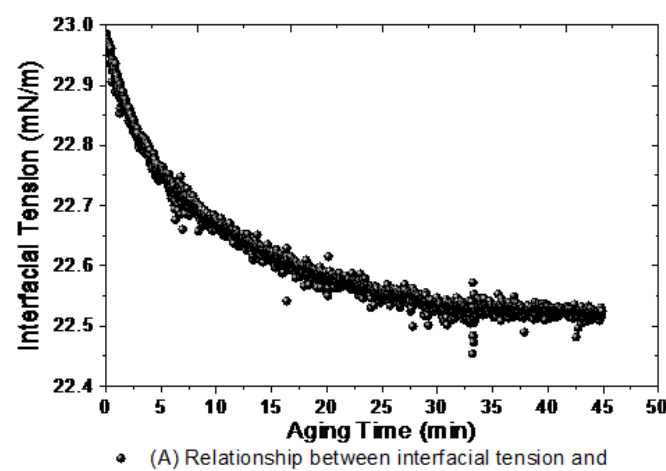

Aging Time for Heavy Oil and Steam

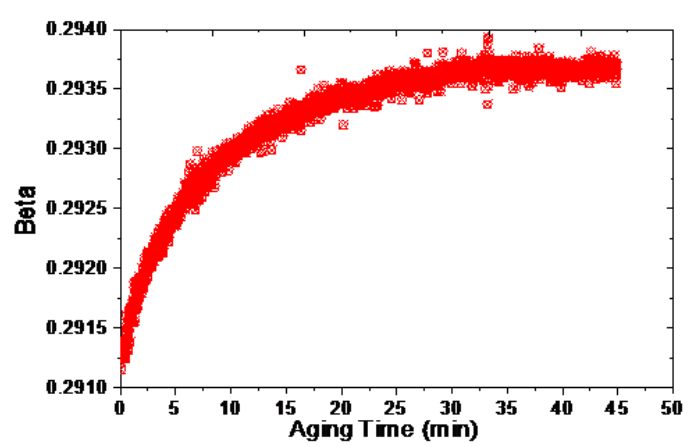

(C) Relationship between Shape Factor and Aging Time for Heavy Oil and Steam

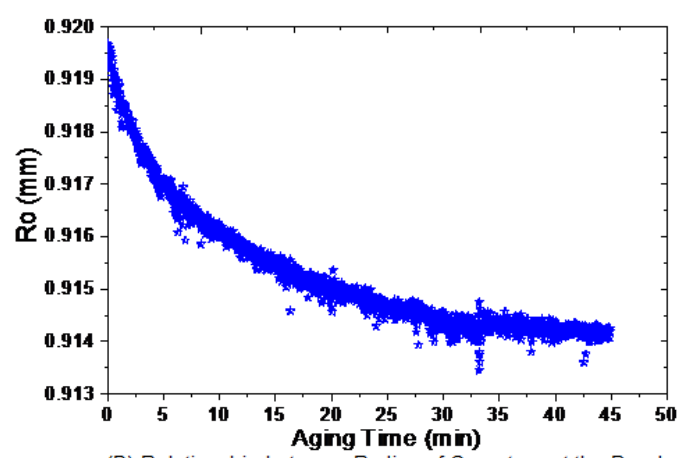

* (B) Relationship between Radius of Curvature at the Drop's Apex and Aging Time for Heavy Oil and Steam

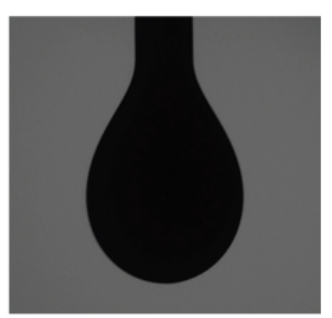

(D) Sequential Digital Image of Pendant Oil Drop in Steam

Figure 9. Interfacial tension measurements and its parameters of heavy-oil/steam system at $115^{\circ} \mathrm{C}$ and $25 \mathrm{psia}$

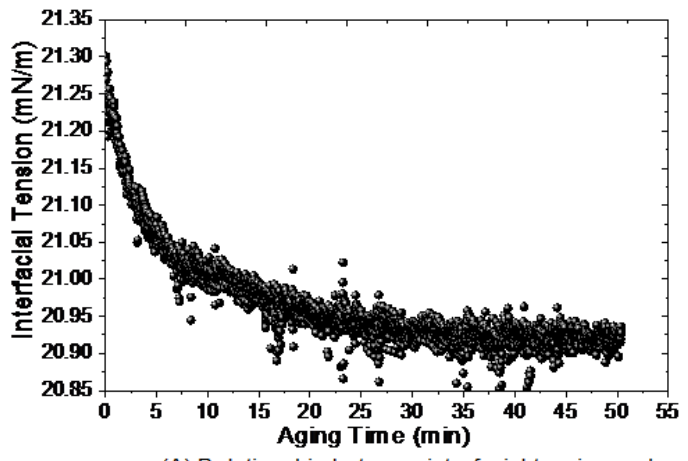

- (A) Relationship between interfacial tension and Aging Time for Heavy Oil and Steam

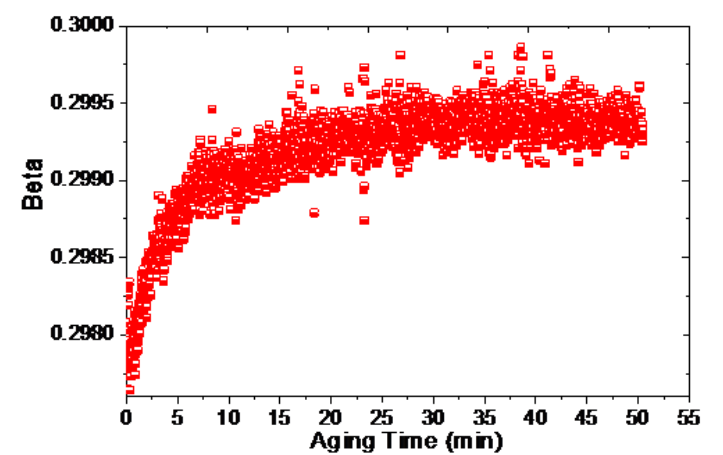

- (C) Relationship between Shape Factor and Aging Time for Heavy Oil and Steam

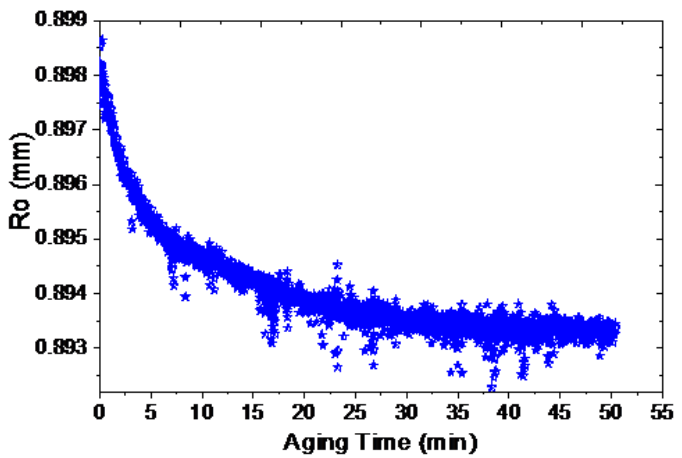

* (B) Relationship between Radius of Curvature at the Drop's Apex and Aging Time for Heavy $\mathrm{O}$ il and Steam

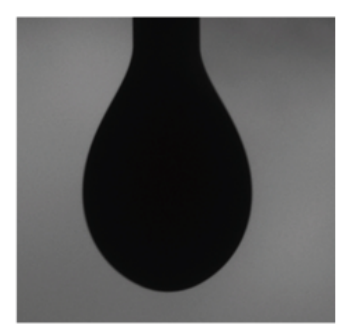

(D) Sequential Digital Image of Pendant Oil Drop in Steam

Figure 10. Interfacial tension measurements and its parameters of heavy-oil/steam system at $138^{\circ} \mathrm{C}$ and $50 \mathrm{psia}$ 


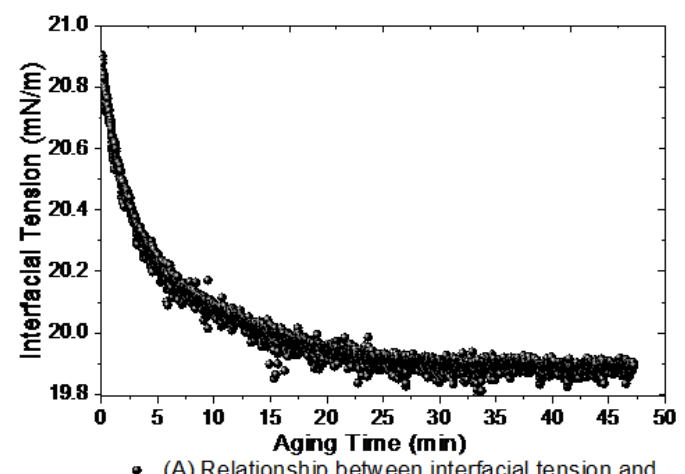

- (A) Relationship between interfacial tension and Aging Time for Heavy Oil and Steam

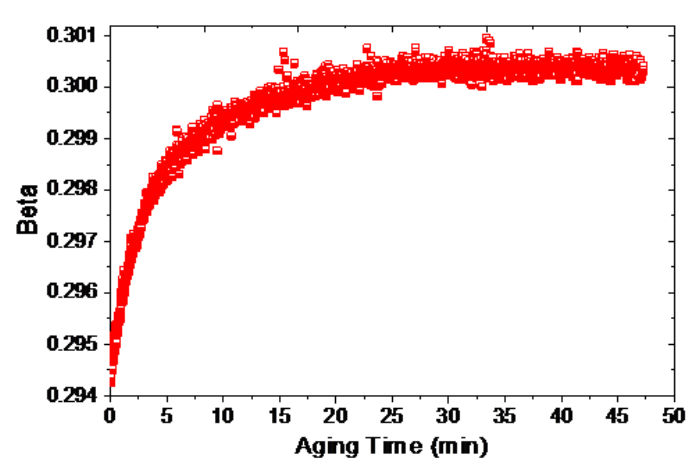

- (C) Relationship between Shape Factor and Aging Time for Heavy Oil and Steam

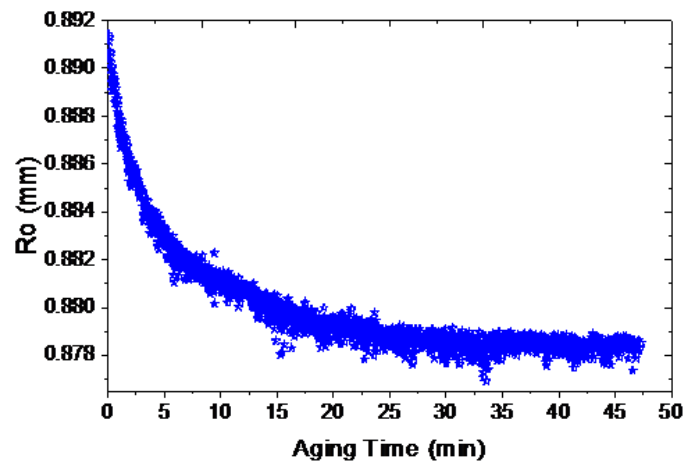

* (B) Relationship between Radius of Curvature at the Drop's Apex and Aging Time for Heavy Oil and Steam

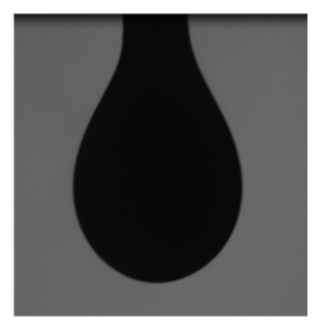

(D) Sequential Digital Image of Pendant Oil Drop in Steam

Figure 11. Interfacial tension measurements and its parameters of heavy-oil/steam system at $164^{\circ} \mathrm{C}$ and $100 \mathrm{psia}$

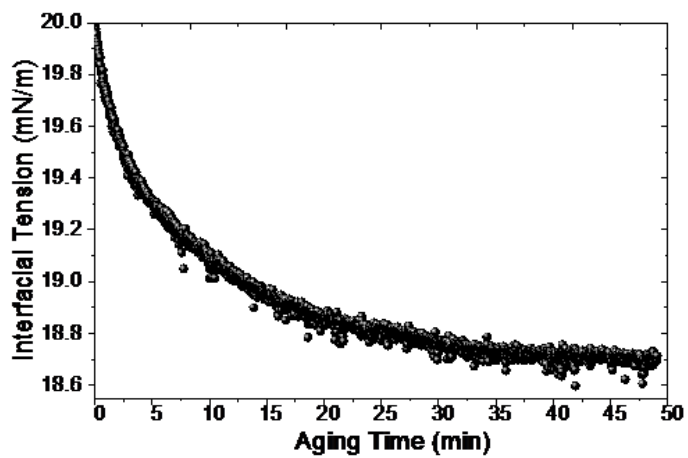

- (A) Relationship between interfacial tension and Aging Time for Heavy Oil and Steam

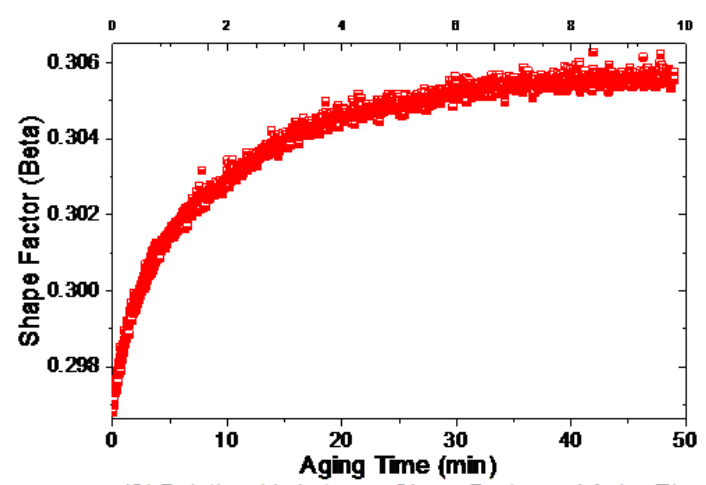

- (C) Relationship between Shape Factor and Aging Time for Heavy Oil and Steam

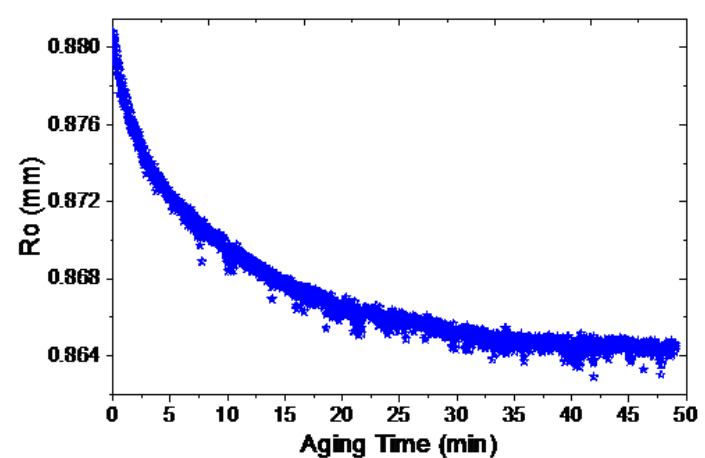

* (B) Relationship between Radius of Curvature at the Drop's Apex and Aging Time for Heavy Oil and Steam

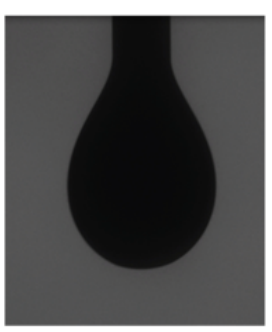

(D) Sequential Digital Image of Pendant Oil Drop in Steam

Figure 12. Interfacial tension measurements and its parameters of heavy-oil/steam system at $181^{\circ} \mathrm{C}$ and $150 \mathrm{psia}$ 
The same phenomena found in this study were also observed by Shariat, et al. 2012 in gas/water systems in which the light intensity affected the accuracy of interfacial tension results (results not shown). Because of these phenomena, the camera or the software cannot read and digitize the droplet correctly. These phenomena can be explained as the size or the shape of the droplet looks like being decreased and sometimes the edge of the droplet is not clear because of a decrease in the light intensity (i.e. too dark). On the other hand, by increasing the light intensity too much (i.e. too bright), the size or the shape of the droplet looks like being increased and sometimes the edge of the droplet is not clear enough compared with the background.

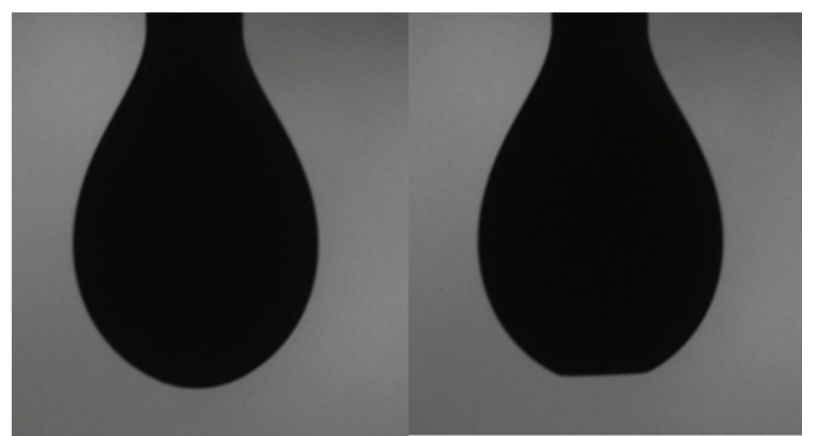

Figure 13. An example of sequential digital image of oil pendant drop in steam with upward and downward movement and wettability alteration

Figure 14 shows the 3D scatter plot comparing the three-test results (Test\#1, Test\#2, and Test\#3) of interfacial tension measurements with its parameters at different saturation temperatures and pressures. It shows that, in general, the interfacial tension decreases with elevating saturation pressure and saturation temperature in all the systems studied as it is clearly shown in Figure 14. As can be seen from the data in the figure, the equilibrium interfacial tension values of all the tests are not very different. For example, the interfacial tension values at saturation pressure of 25 psia and temperature of $115^{\circ} \mathrm{C}$ in Test $\# 1$, \#2, and \#3 are 22.41, 22.44, and $22.52 \mathrm{mN} / \mathrm{m}$, respectively. It is also determined from Figure 15 that the radius of the curve at the oil drop apex decreases with elevating saturation pressure and saturation temperature for all the systems studied with values that are all quite similar. Figure 16 shows the shape factor at different saturation temperatures and pressures in all the three tests.

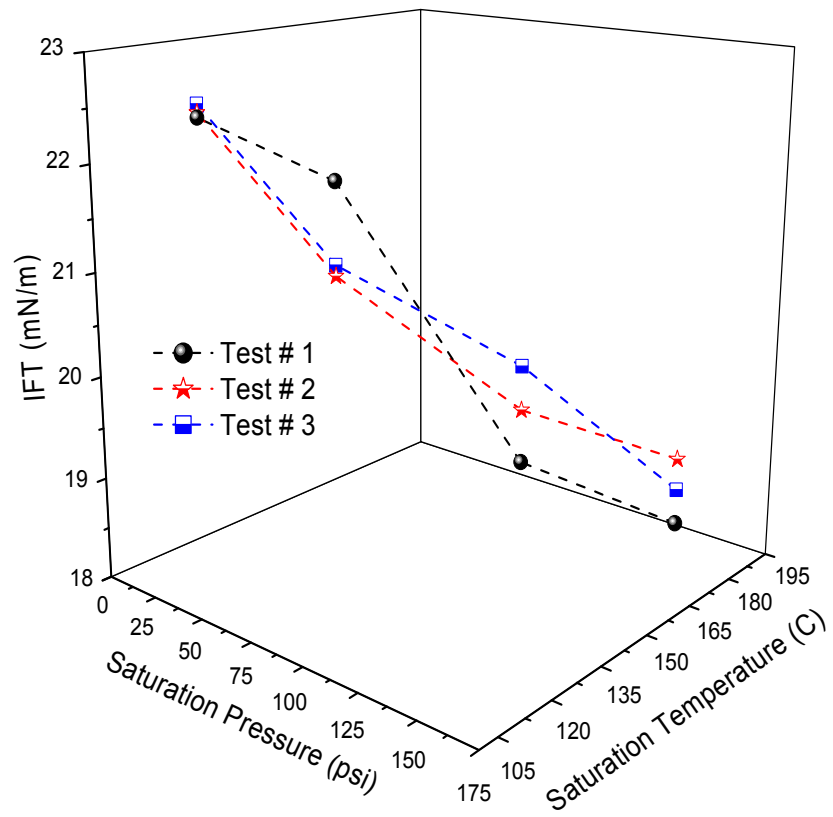

Figure 14. 3-D scatter plot of comparison of three tests of interfacial tension measurements of heavy-oil/steam at different saturation temperature and pressure, (A): Test\#1, (B): Test\#2, (C): Test\#3 


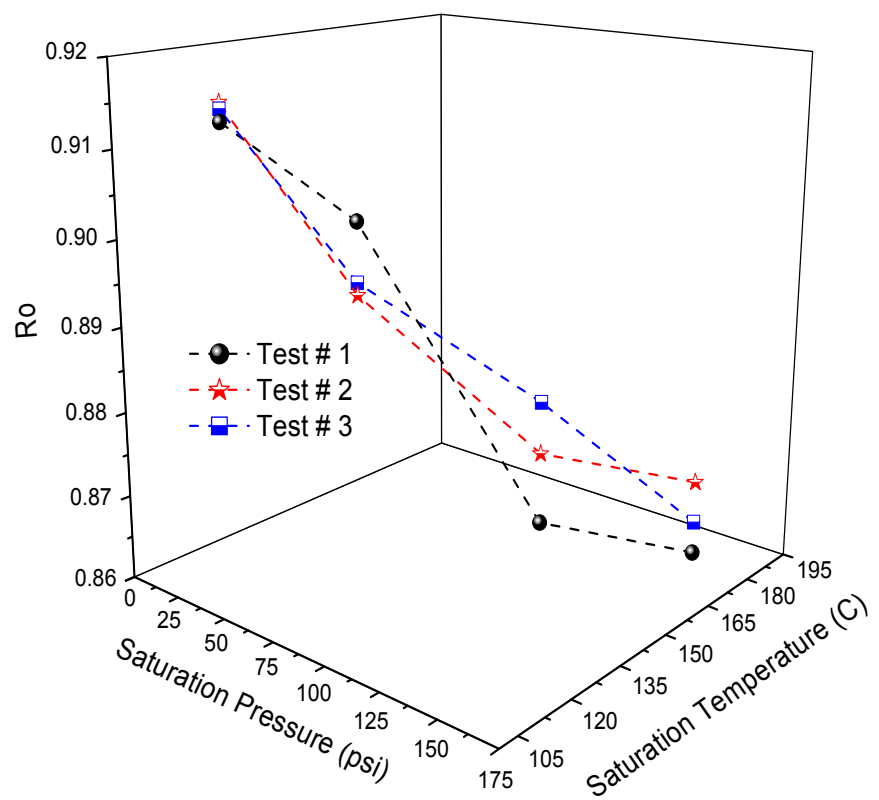

Figure 15. 3-D scatter plot of comparison of three tests of the radius of curvature at the drop apex of heavy-oil/steam at different saturation temperature and pressure, (A): Test\#1, (B): Test\#2, (C): Test\#3

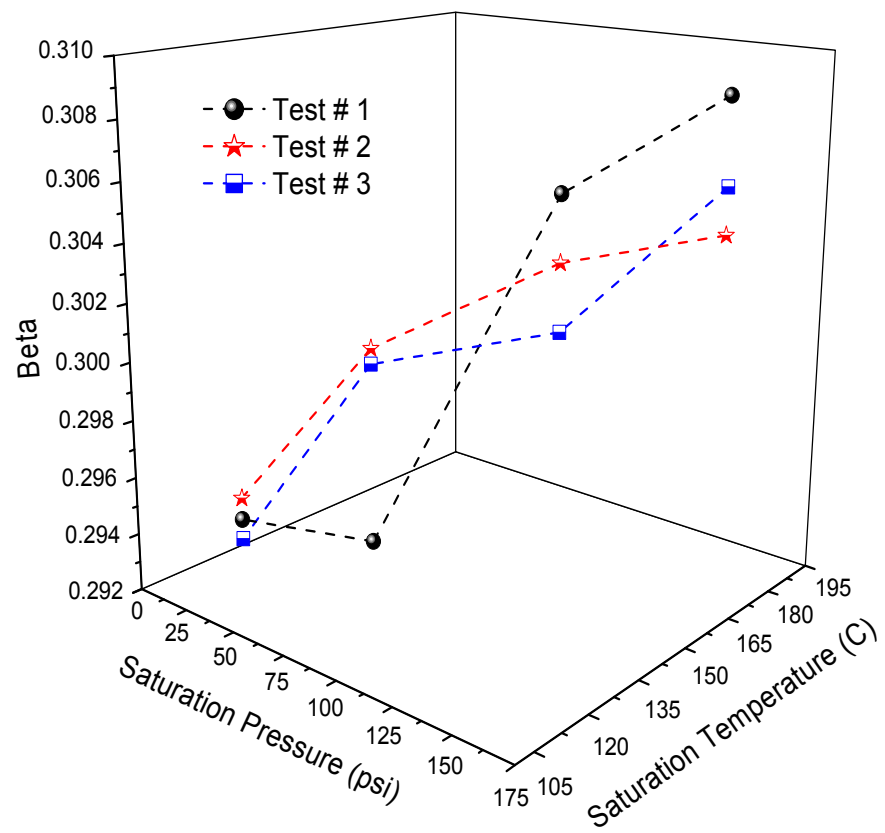

Figure 16. 3-D scatter plot of comparison of three tests of shape factor of heavy-oil/steam at different saturation temperature and pressure, (A): Test\#1, (B): Test\#2, (C): Test\#3

\section{Conclusions}

In this study, we have experimentally investigated and visualized the effects of the saturated steam properties on the interfacial tension of heavy-oil/steam systems and its parameters using the pendant drop method. The experimental setup and procedures were specifically designed to simulate the initial reservoir and steam injection conditions in Duri Field $\left(100 \mathrm{psia}\right.$ and $38{ }^{\circ} \mathrm{C}$, and $\left.0.75 \mathrm{psia} / \mathrm{ft}\right)$. It should be noted here that this experiment has not been completed yet to cover the entire saturation temperature and saturation pressure range. This is because of technical problems and the increase in heat loss at the elevated saturation temperatures. Nevertheless, the research findings shown in this paper can possibly be useful for references and for operating companies as an important source for understanding and visualizing the interfacial tension between steam and heavy oil under a 
specific reservoir condition. Based on the observations and analyses of the results, the main and important conclusions of this study can be briefly described as follows.

- Density calculation results show that the heavy-oil density is decreasing with temperature and pressure entirely because of the effect of temperature rather than pressure whereas the steam density is increasing with temperature and pressure mainly because of the effect of pressure instead of temperature.

- It also indicates that the saturated steam pressure, which corresponds to saturated steam temperature, is exactly the same to that found in the international steam tables.

- Exposing the heavy-oil pendant drop to steam during aging time period results in the maximum oil drop diameter (de) continues to decrease (the volume of the pendant drops tends to be smaller), while the diameter at the distance $d e$ from the drop apex $(d s)$ remains relatively stable. For that reason, it is concluded that the shape factor $(\beta)$ increases during aging time.

- The value of the radius of curvature at the oil drop apex $\left(R_{o}\right)$ decreases during aging time largely because of a decrease in volume or in size of the oil pendant drop. As a result, the interfacial tension of the heavy-oil and steam increases.

- In order to capture and to visualize accurately the shape of the oil pendant drop used for interfacial tension measurement, the light intensity must be adjusted to the optimum condition before the measurement begins.

- Unstable digital images of the heavy-oil pendant drops which are associated with up-ward and down-ward movement during the aging time can also be used for indicating wettability alteration. This phenomenon maybe explained by the tension force between heavy-oil and needle and gravity force of the oil drops.

- Experimental observations show that, in general, steam injection affects the heavy-oil/steam system interfaces and the interfacial tension decreases when the aging time increases in all the systems.

- Combining all the test results of the equilibrium interfacial tension in 3D scatter plot, it can be concluded that the interfacial tension decreases when the saturation pressure and temperature increases in all the systems.

- The experimental observations show a clear trend of interfacial tension at different saturation pressures, different saturation temperatures, and different aging times. It may be useful as an important reference for understanding the heavy-oil/steam interactions.

\section{Current and Future Work}

In the present investigation, pendant drop experiments were conducted at elevated saturation pressure and temperature for steam injection conditions. The results showed a decrease in interfacial tension of a dead-heavy-oil/steam system. To gain a better understanding of the heavy-oil/steam interfacial tension in real reservoir conditions, this research should be continued on different live heavy-oil samples with the maximum saturation pressure of $500 \mathrm{psia}$ and the maximum temperature of $242{ }^{\circ} \mathrm{C}$. Manufacturing a good thermal insulator to reduce the heat loss during steam generation for evaluating higher saturation temperature and investigating the effect of different qualities of steam on the heavy-oil/steam interfacial tension is necessary.

\section{Acknowledgement}

The authors would like to thank to the Department of Energy and Mineral Resources Engineering of Sejong University, South Korea, the Department of Chemical Engineering of Hongik University, South Korea, and the Department of Petroleum Engineering of Bandung Institute of Technology, Indonesia, Chevron Pacific Indonesia.

\section{Nomenclature}

$\gamma \quad$ Surface or interfacial tension of liquid/liquid system $(\mathrm{mN} / \mathrm{m})$.

$\Delta \rho \quad$ Mass density difference between oil drop and steam $\left(\mathrm{g} / \mathrm{cm}^{3}\right)$.

$g$ Gravity constant $\left(\mathrm{cm} / \mathrm{sec}^{2}\right)$.

$R_{o} \quad$ Radius of curvature at the drop apex (mm).

$\beta \quad$ Shape factor.

$S \quad$ Ratio of $d s$ and $d e$.

$d s$ Horizontal diameter of oil drop at a vertical distance of $d e(\mathrm{~mm})$.

de Maximum diameter of oil drop ( $\mathrm{mm})$. 
$\rho_{o} \quad$ Heavy-oil density $(\mathrm{g} / \mathrm{cm} 3)$.

$\rho_{v} \quad$ Steam density $(\mathrm{g} / \mathrm{cm} 3)$.

\section{References}

Ahmed, T. (1989). Hydrocarbon Phase Behavior (1st ed.). Gulf Publishing Company, Houston, Texas.

Donaldson, E. C., \& Alam, W. (2008). Wettability. Gulf Publishing Company, Houston, Texas.

Drelich, J., Fang, Ch., \& White, C. L. (2002). Measurement of Interfacial Tension in Fluid-Fluid Systems, Encyclopedia of Surface and Colloid Science, Marcel Dekker, Inc. 2002, 3152-3166.

Finn, K. H. (2012). DROPimage Advanced Manual, Advanced Edition, University of Oslo, Norway.

Guo, B., \& Schechter, D. S. (1997). A Simple and Accurate Method for Determining Low IFT from Pendant Drop Measurements, International Symposium on Oilfield Chemistry, January 1997, Houston, Texas. http://dx.doi.org /10.2118/37216-MS.

Herd, M. D., Lassahn, G. D., Thomas, C. P., Bala, G. A., \& Eastman, S. L. (1992). Interfacial Tension of Microbial Surfactants Determined by Real-Time Video Imaging of Pendant Drops, SPE/DOE Enhanced Oil Recovery Symposium, January, Tulsa, Oklahoma. http://dx.doi.org /10.2118/24206-MS.

Naser, M. A., Permadi, A. K., Bae, W., Ryoo, W. S., \& Dang, S. T. (2015). A Novel Experimental Method to Generate Steam within a Small Optical Cell for Measuring Interfacial Properties, This paper has been accepted for publication on 13 April 2015 in the Arabian Journal of Science and Engineering, Dhahran, Saudi Arabia. http://dx.doi.org /10.1007/s13369-015-1659-0

Hjelmeland, O. S., \& Larrondo, L. E. (1986). Experimental Investigation of the Effects of Temperature, Pressure, and Crude Oil Composition on Interfacial Properties, Society of Petroleum Engineers, July. http://dx.doi.org /10.2118/12124-PA.

Huygens, R. J. M., Boersma, D. M., Ronde, H., \& Hagoort, J. (1995). Interfacial Tension Measurement of Oil/Water/Steam Systems Using Image Processing Techniques. SPE Advanced Technology Series, 3(March), 129-138. http://dx.doi.org /10.2118/24169-PA.

McCaffery, F. G. (1972). Measurement of Interfacial Tensions and Contact Angles at High Temperature and Pressure. Journal of Canadian Petroleum Technology, 11(July), 26-32. http://dx.doi.org /10.2118/72-03-03

Okasha. T. M., \& Al-Shiwaish, A. J. A. (2010). Effect of Temperature and Pressure on Interfacial Tension and Contact Angle of Khuff Gas Reservoir, Saudi Arabia. SPE/DGS Saudi Arabia Section Technical Symposium and Exhibition, January, Al-Khobar, Saudi Arabia. http://dx.doi.org /10.2118/136934-MS.

PetroWiki (2013). Interfacial tension, Society of Petroleum Engineers Publishing PetroWikiWeb. Retrieved from http://petrowiki.org/Interfacial_tension

Rajayi, M., \& Kantzas, A. (2011). Effect of Temperature and Pressure on Contact Angle and Interfacial Tension of Quartz/Water/Bitumen Systems. Journal of Canadian Petroleum Technology, 50(June), 61-67. http://dx.doi.org /10.2118/148631-PA

Rushing, J. A., Newsham, K. E., Van Fraassen, K. C., Mehta, S. A., \& Moore, G. R. (2008). Laboratory Measurements of Gas-Water Interfacial Tension at HP/HT Reservoir Conditions, CIPC/SPE Gas Technology Symposium Joint Conference, January, Calgary, Alberta, Canada. http://dx.doi.org /10.2118/114516-MS.

Shariat, A., Moore, R. G., Mehta, S. A., Van Fraassen, K. C., \& Rushing, J. A. (2012). Gas/Water IFT Measurements Using the Pendant Drop Method at HP/HT Conditions: The Selected Plane vs. Computerized Image Processing Methods, SPE Annual Technical Conference and Exhibition, January, San Antonio, Texas, USA. http://dx.doi.org /10.2118/159394-MS.

Vargaftik, N. B., Volkov B. N., \& Voljak, L. D., (1983). International Tables of the Surface Tension of Water. Journal of Phys and Chem, 12(October), 817-820.

Wang, W., \& Gupta, A. (1995). Investigation of the Effect of Temperature and Pressure on Wettability Using Modified Pendant Drop Method, SPE Annual Technical Conference and Exhibition, Dallas, Texas, January. http://dx.doi.org /10.2118/30544-MS.

Wang. J., \& Buckley. J. (2002). Standard Procedure for Separating Asphaltenes from Crude Oils, Petroleum Recovery Research Center, Socorro, New Mexico Tech. 2002. http://www.prrc.nmt.edu/groups/petrophysics/media/pdf/prrc_02-02.pdf 
Wolfgang, W., \& Hans-Joachim, K. (2008). International Steam Tables - Properties of Water and Steam based on the Industrial Formulation IAPWS-IF97, Springer.

Worthington, A. M. (1881). On pendant drops, Proceedings of the Royal Society of London 32, pp. 362-37.

Yang, D., \& Gu, Y. (2004). Visualization of Interfacial Interactions of Crude Oil-CO2 Systems under Reservoir Conditions, SPE/DOE Symposium on Improved Oil Recovery, January, Tulsa, Oklahoma. http://dx.doi.org /10.2118/89366-MS.

Yaser, S., Mohammad, A., Hassan, K., \& Ole, T., (2012). Experimental Analyses of Athabasca Bitumen Properties and Field Scale Numerical Simulation Study of Effective Parameters on SAGD Performance, Journal of Energy and Environment Research, 2(1), 140-154. http://dx.doi.org /10.5539/eer.v2n1p140.

\section{Copyrights}

Copyright for this article is retained by the author(s), with first publication rights granted to the journal.

This is an open-access article distributed under the terms and conditions of the Creative Commons Attribution license (http://creativecommons.org/licenses/by/3.0/). 